\title{
Cost-effectiveness analysis in radiology: methods, results and implications
}

\section{Kosteneffektivitätsanalysen in der Radiologie: Methoden, Ergebnisse, Implikationen}

Authors

Matthias F. Froelich ${ }^{1}$, Wolfgang G. Kunz², Fabian Tollens ${ }^{1}$, Moritz L. Schnitzer², Stefan O. Schönberg ${ }^{1}$,

Clemens G. Kaiser ${ }^{1}$, Johannes Rübenthaler ${ }^{2}$

Affiliations

1 Department of Radiology and Nuclear Medicine, University Medical Centre Mannheim, Germany

2 Department of Radiology, University Hospital, LMU Munich, Germany

Key words cost-effectiveness, health economics, healthcare policy

received 20.12 .2020

accepted 26.04.2021

published online 17.06 .2021

Bibliography

Fortschr Röntgenstr 2022; 194: 29-37

DOI 10.1055/a-1502-7830

ISSN 1438-9029

(C) 2021. Thieme. All rights reserved.

Georg Thieme Verlag KG, Rüdigerstraße 14,

70469 Stuttgart, Germany

Correspondence

PD Dr. Matthias F. Frölich

Klinik für Radiologie und Nuklearmedizin, Universitätsmedizin

Mannheim, Theodor-Kutzer-Ufer 1-3, 68167 Mannheim,

Germany

Tel.: +49/6 21/3832067

matthias.froelich@medma.uni-heidelberg.de

Supplementary material is available under

https://doi.org/10.1055/a-1502-7830

\section{ABSTRACT}

Background Diagnostic radiological examinations as well as interventional radiological therapies are performed at a steadily increasing rate amidst increasingly limited resources in healthcare systems. Given their potential to contribute decisively to optimized therapy, in most cases associated shortterm direct costs can be well justified from a clinical perspective. However, to realize their clinical benefits, they must also succeed in justifying them to payers and policymakers. Therefore, the aim of this work is to present suitable methods for economic analysis of radiological precedures and to elaborate their relevance for radiology.

Methodology Methods and metrics of cost-effectiveness analysis are presented and then exemplified using the example cases of MR mammography and interventional treatment of oligometastatic tumor disease of the liver.

Results Cost-effectiveness considerations, taking into account long-term gains in lifespan and quality of life, as well as potential savings through improved treatment planning, do often objectively and credibly justify short-term additional costs.

Conclusions Cost-effectiveness analyses performed with radiological and health economic expertise can support the establishment of new radiological technologies in diagnostics and therapy.

\section{Key Points:}

- When radiological procedures are employed, short-term costs are often offset by significant long-term benefits.

- Radiological examinations and therapies must be justified in the context of limited economic resources.

- Economic methodologies can be used to quantify the quality and cost-effectiveness of radiological methods.

- Such analyses as well as targeted training should be encouraged to provide greater transparency.

\section{Citation Format}

- Froelich MF, Kunz WG, Tollens F et al. Cost-effectiveness analysis in radiology: methods, results and implications. Fortschr Röntgenstr 2022; 194: 29-37

\section{ZUSAMMENFASSUNG}

Hintergrund Diagnostische radiologische Untersuchungen sowie interventionell-radiologische Therapien werden mit stetiger Steigerungsrate im Spannungsfeld zunehmend begrenzter Ressourcen in Gesundheitssystemen durchgeführt. Vor dem Hintergrund ihres Potenzials, zu einer optimierten Therapie entscheidend beizutragen, lassen sich mit ihnen assoziierte kurzfristige, direkte Kosten in den meisten Fällen aus klinischer Sicht gut rechtfertigen. Um ihre klinischen Vorteile jedoch realisieren zu können, muss zusätzlich ihre Rechtfertigung gegenüber Kostenträgern und politischen Entscheidungsträgern gelingen. Ziel dieser Arbeit ist daher, 
geeignete Methoden zur ökonomischen Analyse radiologischer Maßnahmen darzustellen und ihre Relevanz für die Radiologie zu erarbeiten.

Methode Es werden Methoden und Messgrößen der Kosteneffektivitätsanalyse zunächst vorgestellt und dann an den Beispielfällen der MR-Mammografie sowie der interventionellen Behandlung einer oligometastatischen Tumorerkrankung der Leber beispielhaft demonstriert.

Ergebnisse Die Kosteneffektivitätsbetrachtung unter Berücksichtigung langfristiger Gewinne an Lebenszeit und -qua- lität sowie möglicher Einsparpotenziale mittels einer verbesserten Therapieplanung ist oft in der Lage, kurzfristige Zusatzkosten objektiv und glaubwürdig zu rechtfertigen.

Schlussfolgerung Mit radiologischer und gesundheitsökonomischer Expertise durchgeführte Kosteneffektivitätsanalysen können der Rechtfertigung und Etablierung neuer radiologischer Technologien in Diagnostik und Therapie dienen.

$\begin{array}{ll}\text { ABBREVIATIONS } \\ \text { GB-A } & \text { German Federal Joint Committee } \\ \text { ICER } & \text { Incremental cost-effectiveness ratio } \\ \text { IQWiG } & \text { Institute for Quality and Efficiency in Healthcare } \\ \text { MRM } & \text { MR mammography } \\ \text { MWA } & \text { Microwave ablation } \\ \text { NICE } & \text { National Institute for Health and Care Excellence } \\ \text { OMCRC } & \text { Oligometastatic colorectal carcinoma } \\ \text { PET/CT } & \text { Positron emission tomography and computed } \\ & \text { tomography } \\ \text { QALY } & \text { Quality-adjusted life year } \\ \text { QoL } & \text { Quality of life } \\ \text { RFA } & \text { Radiofrequency ablation } \\ \text { SIRT } & \text { Selective internal radiotherapy } \\ \text { WTP } & \text { Willingness-to-pay }\end{array}$

\section{Introduction}

As with other areas of medicine, radiology is subject to increasing cost and resulting justification pressure. The decision-making situation for diagnostic or interventional radiological measures in particular can lead to a strong focus on costs incurred in the short term. Radiology is an integral part of the clinical value chain. In terms of economics, short- and long-term effects must be taken into account. Although the long-term benefits of these measures are in many cases beyond question, it is often difficult to assess the cost/benefit ratio in the clinical environment as well as from the perspective of the healthcare system. While studies and literature on the diagnostic accuracy and efficacy of radiological procedures are frequently available, clinically-oriented studies on economic aspects are often lacking. Although individual issues such as lung cancer screening using computed tomography have already been analyzed with regard to their cost-effectiveness in the long term [1, 2], in many clinical decision-making situations, there is a lack of radiologically initiated, systematic evaluations. The aim of this article is therefore to present the basics of an appropriate cost-effectiveness analysis.

Cost-effectiveness analysis is a method used in health economics to systematically compare different medical strategies in diagnostics, therapy and prevention. The comparison is based on the costs associated with each strategy and the related effectiveness.
Various parameters can define effectiveness here; in the specific case of quantifying medical benefit, the term cost-benefit analysis may also apply in the literature (in this review article, however, the terms are used as synonyms for the sake of simplicity).

The need for medical cost-effectiveness analysis arises, as in other areas, from scarcity of resources. The budget of a health insurance program should lead to a high benefit for the insured (high-value care) [3]. The objective is therefore to reduce therapies without relevant benefit (low-value care) or to replace them with better procedures. However, medical cost-effectiveness analysis as a tool is also limited to certain areas of application, particularly by social and ethical aspects of medical activity.

There is, for example, a legitimate medical and ethical interest in comparing various strategies for the management of high blood pressure or other common diseases in order to maximize the benefits for the insured. In contrast, the comparison of therapies with a preventive and curative approach, for example, is inappropriate. In such cases, the allocation of resources is subject to multifactorial reasons [4]. This article therefore focuses on typical examples of the application of cost-effectiveness analyses in the context of diagnostic and therapeutic procedures in radiology.

\section{Methods}

Different viewpoints can be chosen for a cost-effectiveness assessment including the perspective of the healthcare system or society, the provider or carrier, the patient or the employer. Depending on the perspective, different costs have to be considered, such as direct costs including the cost of a treatment, personnel or material costs, indirect costs including transport costs of the patient or costs due to incapacity to work, as well as intangible costs, which also include non-monetary costs. Often, the perspective of the healthcare system is chosen to evaluate medical services in the context of allocation decisions, and only direct costs, i. e., reimbursed services, are considered.

The current reference standard for quantifying benefits is the quality-adjusted life-year (QALY) [1]. Here, the lifetime gained is not considered in absolute terms, but multiplied by the qualityof-life (QoL) factor. QALY is an assessment of both the quality and quantity of life lived. QoL is primarily assessed using a patient questionnaire. The distribution of medical resources should thus not be based solely on life-prolonging effects, but should also necessarily take into account the quality of life during the anticipated 


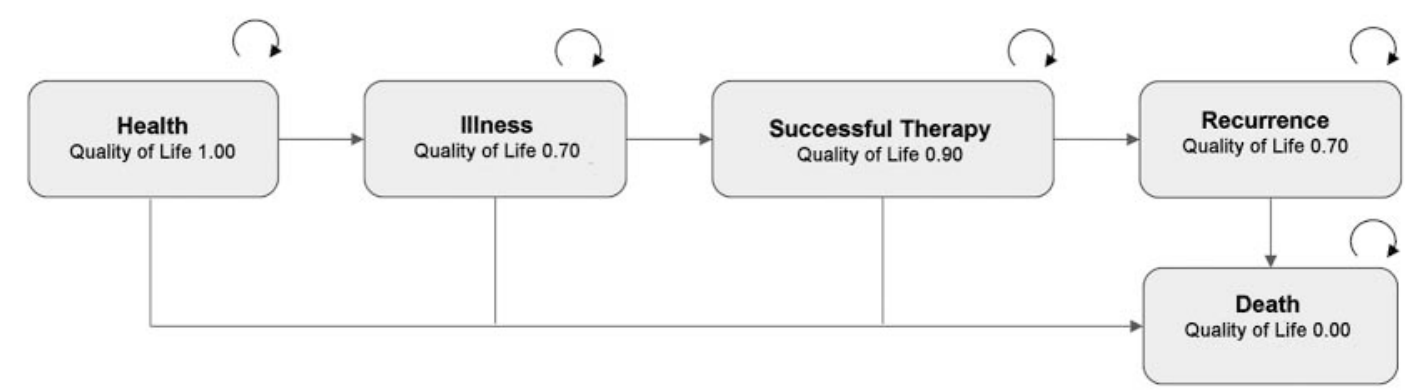

- Fig. 1 General illustration of a Markov model simulating effectiveness and long-term costs. The individual states are assigned qualities of life and, if applicable, ongoing costs. In each cycle, patients can change between states according to predefined probabilities.

time-frame. Healthcare economic evaluation is therefore based on the concept of incremental cost-effectiveness ratio (ICER), which is the result of comparing a new method with the established standard. For the calculation, the additional costs of the method compared to the standard are related to the additional benefits:

$$
\begin{aligned}
\text { ICER } & =\frac{\text { incremental cost }}{\text { incremental effectiveness }} \\
& =\frac{\text { cost of strategy } A-\text { cost of strategy } B}{\text { effectiveness of strategy } A-\text { effectiveness of strategy } B}
\end{aligned}
$$

The benefit of a diagnostic or therapeutic method is quantified in terms of quality-adjusted life years, which is the product of quality of life and length of life. This allows direct comparison of a wide variety of methods on the basis of a common reference value.

Using ICER as a measure of cost-effectiveness can support healthcare decision-makers as a basis for allocation decisions. Thus, a willingness-to-pay threshold can be defined that ranks medical services in terms of reimbursability. In the UK, a threshold of $£ 20000-£ 30000$ per QALY serves as the basis for decisionmaking [5]. For the United States, a threshold of \$50000$\$ 200000$ per QALY has been discussed $[6,7]$. The German Institute for Quality and Efficiency in Health Care (IQWiG) has so far used indication-specific cost-benefit assessments without an absolute threshold based on legal principles [8].

Incremental effectiveness and costs are calculated using healthcare economic modeling and decision analysis. First, a decision tree is constructed that includes the diagnostic or therapeutic methods to be compared as well as all feasible outcomes. To model the long-term costs and benefits, a Markov model is constructed that simplistically defines different health states but realistically represents the real variety of existing states ( $\bullet$ Fig. 1$)$. A simulated case is in a state of health in each cycle of the model and, if necessary, changes this state according to predefined probabilities at the beginning of each new cycle. The respective condition is characterized by a defined quality of life as well as associated costs. If the duration of a cycle is multiplied by the quality of life, the resulting benefit results in the form of qualityadjusted life years. For example, the Markov model can be used to represent the progression of disease through a disease stage, a recovery stage, to recurrence or death; each of the states occurs with a given probability and results in ongoing costs, if applicable. The simulation over a period of time allows determination of the cumulative mean costs and QALYs for all strategies and calculation of the incremental cost-effectiveness rate. Comprehensive sensitivity analyses examine the uncertainty of the various variables and their impact on the model and the resulting ICER.

In a cost-effectiveness plane, several studies/interventions can be compared with respect to their incremental costs and benefits ( $\triangleright$ Fig. 2). If a strategy is cost-saving and generates more benefits than the standard strategy, it is positioned in the lower right quadrant as the dominant strategy. If a strategy is more costly than the standard and shows less benefit, the strategy is said to be dominated (upper left quadrant). The cost-effectiveness ratio can be calculated if a strategy costs more than the standard and generates more benefits. A straight line through the zero point with a slope in cost/QALY represents the willingness-to-pay threshold.

Appropriate quality control recommendations are available for the preparation of cost-effectiveness analyses $[9,10]$ which are summarized in $>$ Table 1.

\section{Cost-effectiveness analysis of diagnostic procedures using the example of MR mammography}

Cost-effectiveness analyses play a particularly important role for imaging techniques that indisputably offer additional diagnostic benefits, but which are considered to be more expensive, at least in the short term, compared with established imaging techniques. Here, it is important to assess how great the additional benefit, the exact diagnostic and prognostic differences, and accordingly the cut-off value (ICER) are with respect to the costbenefit ratio of the two comparative methods.

In current national breast cancer screening, X-ray-based conventional mammography is used every two years in women between the ages of 50 and 70 , regardless of the individual patient's breast density [11].

According to the literature, patients with dense breast tissue have an increased risk of breast cancer, regardless of their genetic predisposition, while it is known that the sensitivity of mammo- 


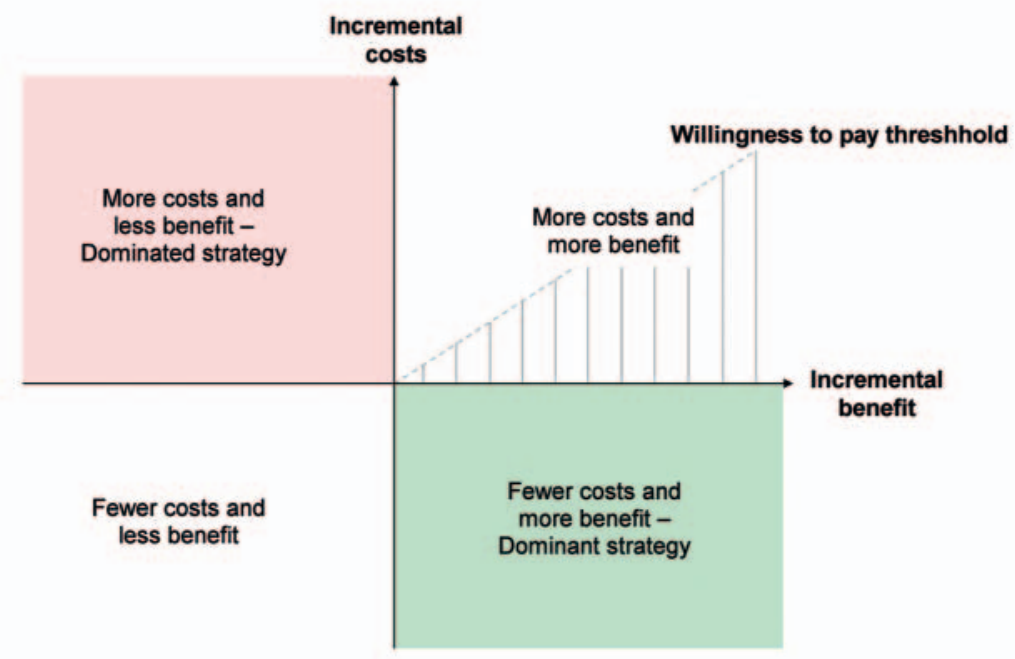

Fig. 2 Cost-effectiveness plane: Incremental benefits and incremental costs compared to the standard. The shaded area below the willingnessto-pay threshold denotes the area of cost-effective strategies.

graphy in dense glandular tissue is sometimes less than $50 \%$ [12]. In this case, there may be a reasonable opportunity to involve alternative, more sensitive procedures and include them in breast cancer screening, thereby increasing diagnostic efficiency, i. e., cost-effectiveness.

MR mammography (MRM) is a much more sensitive method in this regard, but it also appears to be more cost-intensive at first. Several multicenter studies have demonstrated that, in purely diagnostic terms, even a combination of all conventional imaging modalities does not outperform the diagnostic accuracy of MRM $[13,14]$. This method is therefore already used as standard in high-risk screening. Initial cost-effectiveness analyses showed indications of cost-effective use with regard to this application several years ago $[15,16]$.

However, because data on MR mammography have been limited to use in the high-risk segment, only sparse analyses have been available regarding MR mammography for women at intermediate risk for breast cancer due to their increased breast density.

However, recent studies have shown that the use of MR mammography for screening women with dense breasts significantly reduced interval cancer rates compared to conventional imaging options [17]. At the same time, this new data provided the opportunity for initial cost-effectiveness analyses in this hitherto new segment.

Using these data, decision models for cost-effectiveness analyses can be generated and evaluated accordingly. - Fig. 3a shows an example of a possible decision model for breast cancer screening in high-risk women that allows comparison of multiple strategies. A Markov model, as shown in ₹ Fig. 3b, allows modeling of costs and benefits over time ( $\triangleright$ Table S1). For mammography, ultrasound, the combination of mammography and ultrasound, and MR mammography, this model yields cumulative costs of $\$ 36202$, \$36 668, \$37 984, and \$39051 over a 30-year period, and cumulative effects of 19.53, 19.53, 19.55, and 19.59 QALYs, respectively. MR mammography would be a cost-effective strate- gy at an ICER of \$45 374 per QALY compared with standard mammography.

For women at intermediate risk for breast cancer, it has been shown that examination by MRM can prevent or reduce other costs in the medium and long term due to the often high breast density, despite significantly higher initial examination costs (operational) $[18,19]$. This is achieved through the collection of prognostically valuable, therapy-relevant information. In these analyses, ICER values for MRM compared with mammography were consistently found to be well below the willingness-to-pay values described for Western industrialized countries. From this it can be concluded that MRM in these patient cohorts is definitely a suitable imaging modality from an economic point of view in addition to the above-mentioned medical arguments.

\section{Cost-effectiveness consideration of interven- tional radiological treatments using ablation of hepatic metastases as an illustration}

In addition to advances in diagnostic imaging, the clinical added value of interventional, minimally invasive image-guided procedures can increasingly be demonstrated by a large number of prospective studies. Since both microtherapeutic procedures such as prostate embolization or selective internal radiotherapy (SIRT), vasodilation procedures, or CT- and MRI-guided ablative procedures are sometimes associated with substantial initial costs, it is crucial to also transparently present their economic added value with respect to the entire treatment process. This will be illustrated using the example of the application of ablative procedures in oligometastatic tumor disease of the liver.

Oligometastatic colorectal carcinoma (omCRC) is a very common tumor entity associated with tumor disease of the liver, characterized by the presence of 3 to 5 liver metastases, which have spread from a colorectal carcinoma via the portal venous system 
- Table 1 Checklist for cost-effectiveness analysis.

\begin{tabular}{|c|c|}
\hline item & instruction \\
\hline Title & $\begin{array}{l}\text { Running title of the study and identification } \\
\text { as cost-effectiveness analysis }\end{array}$ \\
\hline Abstract & $\begin{array}{l}\text { Structured summary containing objectives, } \\
\text { material and methods, results and conclu- } \\
\text { sions }\end{array}$ \\
\hline \multicolumn{2}{|l|}{ Introduction } \\
\hline Background & $\begin{array}{l}\text { Background of the study and contextual } \\
\text { transition to the key question of the study }\end{array}$ \\
\hline Key question & Aim of the analysis \\
\hline \multicolumn{2}{|l|}{$\begin{array}{l}\text { Material and } \\
\text { methods }\end{array}$} \\
\hline Target population & Characteristics of target population \\
\hline Comparators & $\begin{array}{l}\text { Description of the compared diagnostic or } \\
\text { interventional modalities }\end{array}$ \\
\hline Period of time & Time span considering results and patients \\
\hline Discount rate & $\begin{array}{l}\text { Determination of discount rate for costs and } \\
\text { results }\end{array}$ \\
\hline Utility & Fixation of a health outcome value (QALY) \\
\hline Input parameter & $\begin{array}{l}\text { Determination of all input parameters used } \\
\text { for model calculation }\end{array}$ \\
\hline $\begin{array}{l}\text { Model choice and } \\
\text { description }\end{array}$ & $\begin{array}{l}\text { Choice and description of the utilized model } \\
\text { f. e. Markov model with its pathways and } \\
\text { state transitions }\end{array}$ \\
\hline $\begin{array}{l}\text { Measurement } \\
\text { and evaluation of } \\
\text { effectivity }\end{array}$ & $\begin{array}{l}\text { Comparison of costs and effectiveness and } \\
\text { description outcome value (ICER) }\end{array}$ \\
\hline Costs and utilities & $\begin{array}{l}\text { Determination of costs and utilities utilized } \\
\text { in the study }\end{array}$ \\
\hline Sources & $\begin{array}{l}\text { Description of the sources of the utilized } \\
\text { input parameters }\end{array}$ \\
\hline \multicolumn{2}{|l|}{ Results } \\
\hline $\begin{array}{l}\text { Model case } \\
\text { results }\end{array}$ & $\begin{array}{l}\text { Results of cost-effectiveness analysis, } \\
\text { incremental costs and ICER }\end{array}$ \\
\hline $\begin{array}{l}\text { Stability and } \\
\text { uncertainty }\end{array}$ & $\begin{array}{l}\text { Results of deterministic and probabilistic } \\
\text { sensitivity analyses }\end{array}$ \\
\hline Figures & $\begin{array}{l}\text { Graphics illustrating results of cost-effec- } \\
\text { tiveness analysis and sensitivity analyses }\end{array}$ \\
\hline \multicolumn{2}{|l|}{ Discussion } \\
\hline $\begin{array}{l}\text { Context } \\
\text { references }\end{array}$ & Clinical context of the results \\
\hline $\begin{array}{l}\text { Relevance of } \\
\text { study results }\end{array}$ & $\begin{array}{l}\text { Describing the relevance of results in context } \\
\text { of health policy and health economics }\end{array}$ \\
\hline Limitations & $\begin{array}{l}\text { Limitation of the study and discussion of } \\
\text { robustness and uncertainty }\end{array}$ \\
\hline $\begin{array}{l}\text { Ethical } \\
\text { implications }\end{array}$ & Ethical implications of study results \\
\hline Disclosure & $\begin{array}{l}\text { Potential conflict of interest regarding a } \\
\text { funding source or other sources of support }\end{array}$ \\
\hline
\end{tabular}

[20]. Surgical therapy is sometimes viewed as the only curative option for treating omCRC. Since the hepatic metastases are often too close to vital vessels, and sometimes both liver lobes are affected, only about $25 \%$ of all patients are ideally suited for an operation. This makes the interventional radiological options of treatment with respect to ablation all the more relevant to provide the patient with effective therapy, improved quality of life, and possibly improved overall survival [21]. According to studies, ablative therapy such as radiofrequency or microwave ablation in the treatment of non-operable omCRCs supports significantly improved overall survival, which is why this therapeutic principle is also recommended in the ESMO guidelines for the treatment of metastatic colorectal carcinoma - also in combination with other procedures $[22,23]$. Here, particular attention must be paid to ensuring a tumor-free ablation margin of at least $>5 \mathrm{~mm}$ by the interventional radiologist to effectively prevent post-ablation tumor progression [24]. This treatment strategy therefore is not only within the guidelines, but can also be recommended from an economic point of view when effective [25, 26]. > Fig. 4a provides an example of an appropriate decision model for comparing therapeutic strategies when treating oligometastatic tumor disease. Associated long-term costs as well as long-term cost-effectiveness can then be projected using a Markov model as in - Fig. 4b. The corresponding input parameters for the model must be defined for the model. $>$ Table $\mathbf{S 2}$ of the Supplement summarizes examples of input parameters selected from the literature. Based on these figures, when calculated over the lifetime of patients for resection, radiofrequency ablation (RFA), and microwave ablation (MWA), respectively, the cumulative costs are $\$ 41847.96$; $\$ 36936.90$; and $\$ 35234.26$, with an effectiveness of $6.80,6.30$, and 6.95 QALYs, respectively. Thus, in this case, MWA would be the dominant strategy because it is associated with overall lower costs and better effectiveness than the other two strategies. However, this result is only intended to illustrate an example of the procedure and interpretation of the results of a cost-effectiveness analysis. In this case, an additional sensitivity analysis is warranted to check the robustness of the results.

After initial treatment, regular imaging therapy monitoring is crucial for the further course of the disease. Here, investigations using 18F-FDG PET/CT can detect both incomplete ablation and recurrent disease at the ablation margins. The strategy of followup using 18F-FDG PET/CT provides a significant cost reduction compared to $\mathrm{CT}$ alone despite initially higher financial expenditure, as the cost of overlooked disease is significantly higher. This not only improves overall survival, but also effectively reduces the general cost of treatment [27].

\section{Healthcare policy aspects}

Decision-makers in healthcare systems are faced with the challenge of performing cost-effectiveness analyses requiring consideration of multifarious factors in the overall policy context [28]. The concept of cost-effectiveness analyses presented by the authors in this review represents the most widely used methodology in the healthcare system in order to be able to adequately distribute limited resources that can be made available in the respec- 


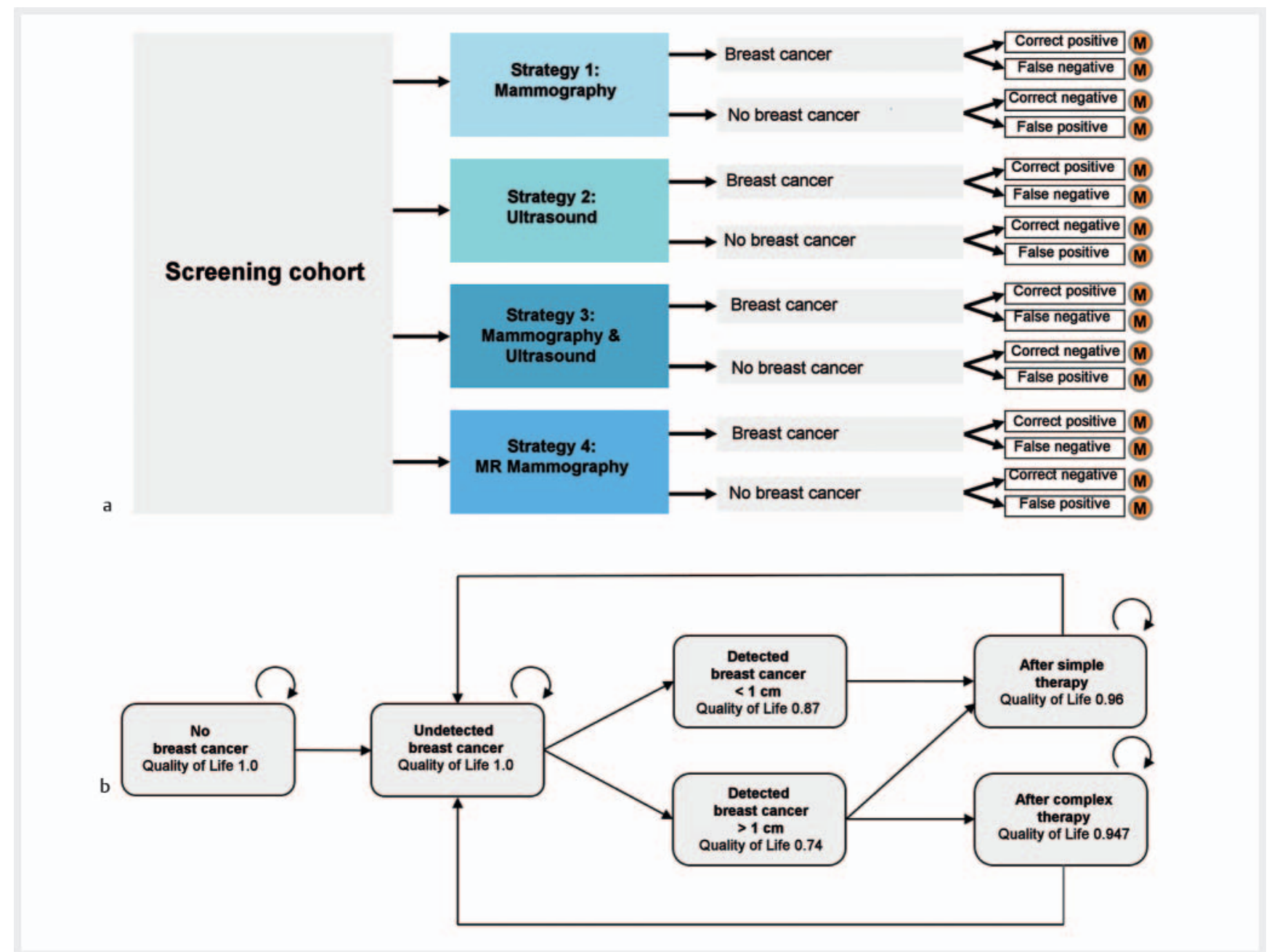

- Fig. 3 Illustration of a diagnostic decision model. a Decision model for screening patients for the presence of breast cancer. b Markov model for estimating long-term costs and long-term effectiveness.

tive healthcare system within society ( $\triangleright$ Fig. 5) [29]. Thus, in the macroeconomic context, any amount made available for the healthcare system, for example, is no longer available for education. Overall, this harbors potential for conflict, especially in economies with clearly limited resources $[30,31]$. In the United Kingdom, for example, the National Institute for Health and Care Excellence (NICE) makes approval of the reimbursability of innovative treatments conditional, among other things, on the availability of a corresponding cost-effectiveness analysis taking into account the respective QALYs. Likewise, in Germany, the "Law to Strengthen Competition in Statutory Health Insurance” (GKVWSG) came into force on April 1, 2007, whereby Section 35b SGB V was revised. The Federal Joint Committee (G-BA) was authorized to commission the Institute for Quality and Efficiency in Health Care (IQWiG) in accordance with Section 139b (1) SGB V to evaluate future services according to their costs and benefits and not only regarding their potential benefits, as was formerly the case. In principle, IQWiG is not bound by fixed criteria with regard to the use of certain methods for evaluating cost-benefit ratios; however, it must be based on "international standards of evidence-based medicine and health economics recognized in the respective specialist groups" and must include these standards in its decision-making process. Some critics of cost-effectiveness analyses express concern that considering only QALYs and corresponding ICERs could lead to limitations in the potential treatment options available to patients, thereby denying treatment options that are "too expensive". It should be noted here that cost-effectiveness analyses based on scientific evidence can inform payers and providers in the health care system that the ultimate decision regarding the reimbursability of necessary services must be viewed both in the context of the individual patient case as well as the context of the performance of the individual health care system and its infrastructure. The thresholds of \$5000-\$200 000 per QALY presented for the USA, for example, should not be regarded as absolute limits, but rather as guideline values that do not apply in Germany in particular, since IQWiG does not define absolute thresholds. With respect to the healthcare policy debate on the reimbursability of radiological services, it is important to discuss which threshold values should be used that lead to a significantly improved benefit for the patient when comparatively "more expensive" diagnostics are used. The discontinuation of method evaluation procedures by the Joint 


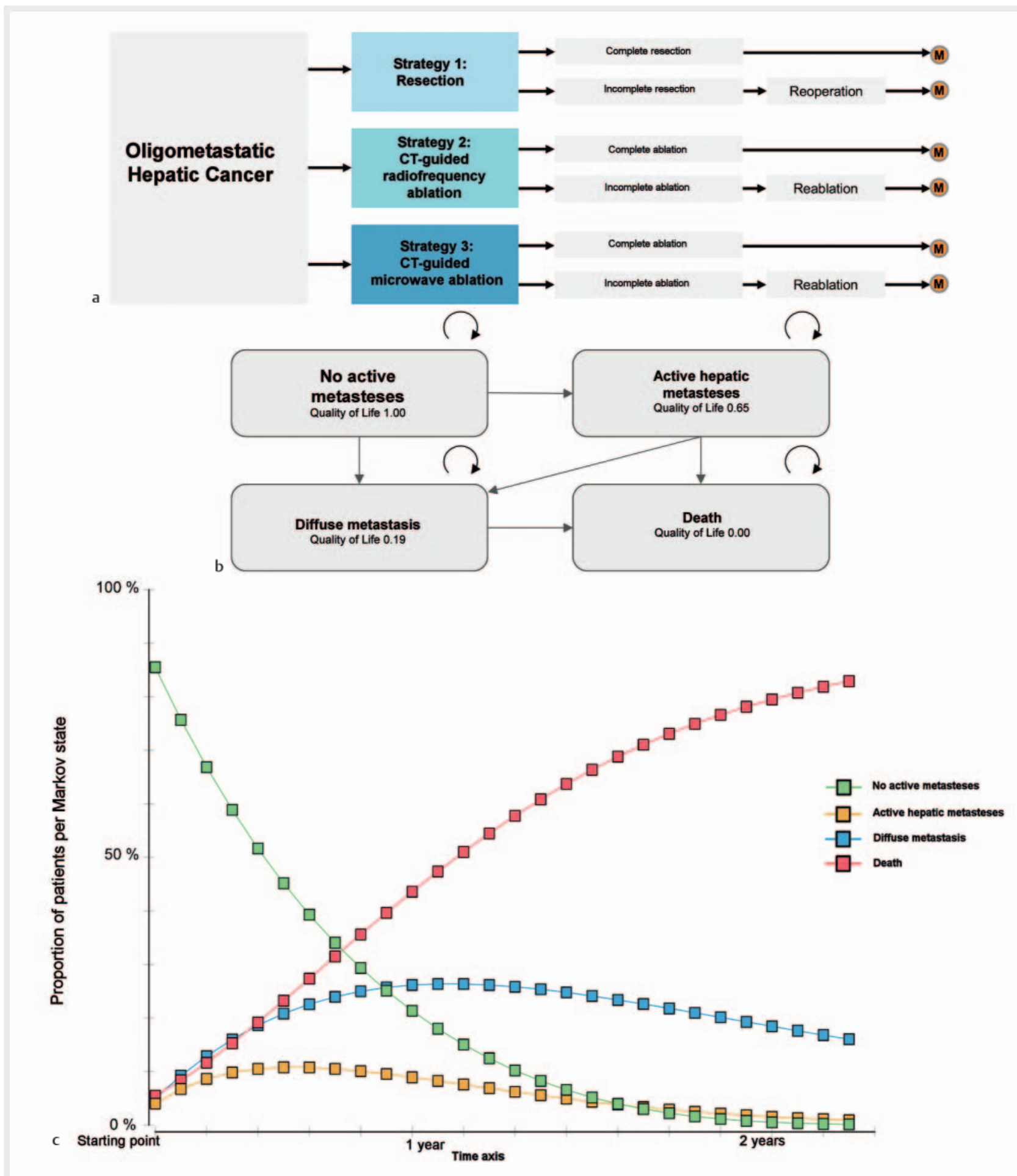

- Fig. 4 Illustration of a therapeutic decision model. a Decision modeling for interventional therapy of liver lesions for the treatment of oligometastatic tumor disease of the liver. $\mathbf{b}$ Example of a simple Markov model for modeling patient-specific outcomes. The starting state of the patients is based on the decision model (e. g., after incomplete resection, starting in the "active hepatic metastases" state). c Monthly modeling of Markov states after complete microwave ablation.

Federal Committee for the diagnostic combination of positron emission tomography and computed tomography (PET/CT) communicated in November 2020 illustrates the importance of costeffectiveness analysis to prove the tangible benefit of supposedly "expensive" examination techniques [27, 32]. It is worth mentioning here that IQWiG, which was commissioned by the G-BA, developed its own two-stage procedure for Germany, in which in the first step only the benefit is assessed and only in the case of an 


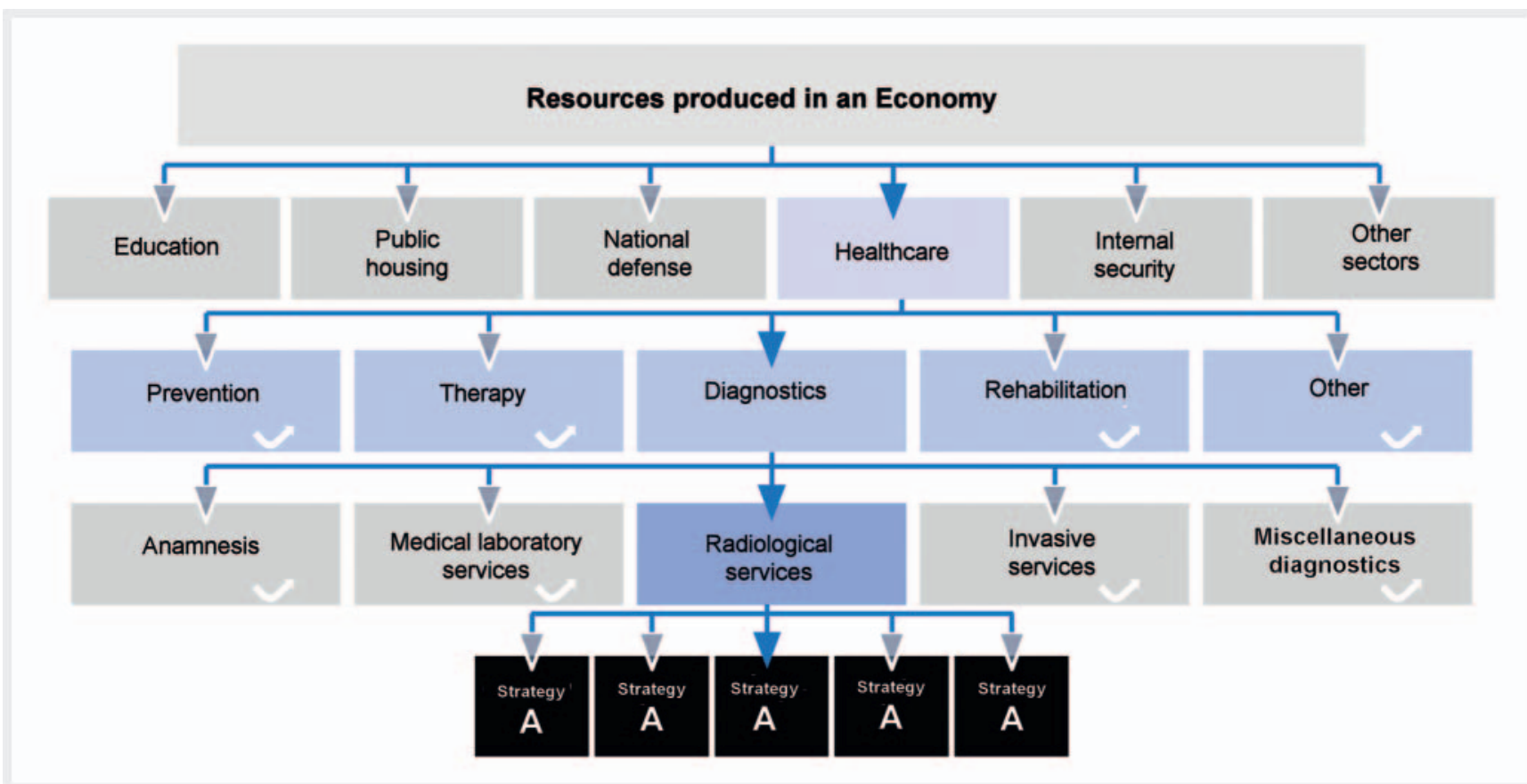

- Fig. 5 Different levels of resource allocation within an economy and their associated entry points for cost-effectiveness analyses along the value chain.

increased benefit compared to the standard treatment, in the second step an assessment is performed of the benefit in comparison to the costs, e. g. by demonstrating a cost-effectiveness analysis. Addressing the relevant analyses is also the task of the respective professional associations. For example, within the German X-ray Society, the Working Group on Health Policy Responsibility is concerned with identifying appropriate innovative methods and promoting their implementation in day-to-day care for the benefit of patients, e. g. by carrying out cost-effectiveness analyses.

\section{Outlook}

Using cost-effectiveness analyses, it is possible to model the effect of diagnostic and interventional radiology methods in the short and long term. In radiology in particular, short-term costs are often offset by long-term gains in quality of life and longevity, as well as potential savings through better therapy planning. Thus, this methodology has enormous potential, especially for radiology, by demonstrating and communicating the benefits of diagnostic methods and interventional therapies. As discussed above, economic analyses, and cost-effectiveness considerations in particular, are explicit bases of reimbursement eligibility decisions in many healthcare systems [33].

Radiological expertise is essential for the identification of relevant issues as well as realistic modeling of the clinical value chain. It is therefore imperative that corresponding analyses be performed either by radiologists with appropriate economic qualifications or by interdisciplinary teams taking radiological expertise into account to ensure the clinical significance and technical accuracy of the results. It would therefore be advisable, for example, to set up appropriate working groups within national and international radiological societies and to specifically promote targeted training in relevant economic analysis. Also due to its model-like character, interdisciplinary as well as cross-site collaboration lends itself to cost-effectiveness considerations.

\section{Conflict of Interest}

Department of Radiology and Nuclear Medicine, University Medical Center Mannheim: Research Agreement with Siemens

References

[1] Mahadevia PJ, Fleisher LA, Frick KD et al. Lung Cancer Screening With Helical Computed Tomography in Older Adult Smokers: A Decision and Costeffectiveness Analysis. JAMA 2003; 289: 313

[2] Black WC, Gareen IF, Soneji SS et al. Cost-Effectiveness of CT Screening in the National Lung Screening Trial. 2014 http://Dx.Doi.Org/10.1056/NEJ Moa1312547

[3] Pandya A. Adding Cost-effectiveness to Define Low-Value Care. JAMA 2018; 319: 1977-1978

[4] Hunink MGM, Weinstein MC, Wittenberg E et al. Decision making in health and medicine: Integrating evidence and values. Cambridge University Press. 2014

[5] Guide to the Methods of Technology Appraisal 2013 [Internet] - PubMed.

[6] Cameron D, Ubels J, Norström F. On what basis are medical cost-effectiveness thresholds set? Clashing opinions and an absence of data: a systematic review. Glob Health Action 2018; 11: 1447828

[7] McDougall JA, Furnback WE, Wang BCM et al. Understanding the global measurement of willingness to pay in health. J Mark Access Health Policy 2020; 8 [published online ahead of print] 
[8] Gandjour A. Willingness to pay for new medicines: a step towards narrowing the gap between NICE and IQWiG. BMC Health Serv Res 2020; 20: 343

[9] Sanders GD, Neumann PJ, Basu A et al. Recommendations for Conduct, Methodological Practices, and Reporting of Cost-effectiveness Analyses. JAMA 2016; 316: 1093

[10] Husereau D, Drummond M, Petrou S et al. Consolidated Health Economic Evaluation Reporting Standards (CHEERS) statement. Eur J Health Econ 2013; 14: 367-372

[11] Leitlinienprogramm Onkologie: Mammakarzinom.

[12] Pisano ED, Gatsonis C, Hendrick E et al. Diagnostic Performance of Digital versus Film Mammography for Breast-Cancer Screening. N Engl J Med 2005; 353: 1773-1783

[13] Sardanelli F, Podo F, Santoro F et al. Multicenter surveillance of women at high genetic breast cancer risk using mammography, ultrasonography, and contrast-enhanced magnetic resonance imaging (the high breast cancer risk italian 1 study): final results. Invest Radiol 2011; 46: 94-105

[14] Kuhl C, Weigel S, Schrading S et al. Prospective multicenter cohort study to refine management recommendations for women at elevated familial risk of breast cancer: the EVA trial. J Clin Oncol Off J Am Soc Clin Oncol 2010; 28: 1450-1457

[15] Ahern CH, Shih YCT, Dong W et al. Cost-effectiveness of alternative strategies for integrating MRI into breast cancer screening for women at high risk. Br J Cancer 2014; 111: 1542-1551

[16] Moore SG, Shenoy PJ, Fanucchi L et al. Cost-effectiveness of MRI compared to mammography for breast cancer screening in a high risk population. BMC Health Serv Res 2009; 9: 1-8

[17] Bakker MF, de Lange SV, Pijnappel RM et al. Supplemental MRI Screening for Women with Extremely Dense Breast Tissue. N Engl ] Med 2019; 381 : 2091-2102

[18] Froelich MF, Kaiser CG. Cost-effectiveness of MR-mammography as a solitary imaging technique in women with dense breasts: an economic evaluation of the prospective TK-Study. Eur Radiol 2020; 31: 967-974

[19] Kaiser CG, Dietzel M, Vag T et al. Cost-effectiveness of MR-mammography vs. conventional mammography in screening patients at intermediate risk of breast cancer - A model-based economic evaluation. Eur J Radiol 2020; 109355 [published online ahead of print]

[20] Petersen C, Gauer T. [Local ablative radiotherapy of oligometastatic colorectal cancer]. Radiol 2017; 57: 105-110
[21] Engstrand J, Nilsson H, Strömberg C et al. Colorectal cancer liver metastases - a population-based study on incidence, management and survival. BMC Cancer 2018; 18: 78

[22] Van Cutsem E, Cervantes A, Adam R et al. ESMO consensus guidelines for the management of patients with metastatic colorectal cancer. Ann Oncol Off J Eur Soc Med Oncol 2016; 27: 1386-1422

[23] Ruers T, Van Coevorden F, Punt CJA et al. Local Treatment of Unresectable Colorectal Liver Metastases: Results of a Randomized Phase II Trial. J Natl Cancer Inst 2017

[24] Shady W, Petre EN, Do KG et al. Percutaneous Microwave versus Radiofrequency Ablation of Colorectal Liver Metastases: Ablation with Clear Margins (A0) Provides the Best Local Tumor Control. J Vasc Interv Radiol JVIR 2018; 29: 268-275.e1

[25] Gazelle GS, McMahon PM, Beinfeld MT et al. Metastatic colorectal carcinoma: cost-effectiveness of percutaneous radiofrequency ablation versus that of hepatic resection. Radiology 2004; 233: 729-739

[26] Froelich MF, Schnitzer ML, Rathmann N et al. Cost-Effectiveness Analysis of Local Ablation and Surgery for Liver Metastases of Oligometastatic Colorectal Cancer. PMID: 33806059. PMCID: PMC8037107. doi:10.3390/cancers13071507

[27] Schnitzer ML, Froelich MF, Gassert FG et al. Follow-Up 18F-FDG PET/CT versus Contrast-Enhanced CT after Ablation of Liver Metastases of Colorectal Carcinoma-A Cost-Effectiveness Analysis. Cancers 2020; 12

[28] Franklin M, Lomas J, Walker S et al. An Educational Review About Using Cost Data for the Purpose of Cost-Effectiveness Analysis. PharmacoEconomics 2019; 37: 631-643

[29] de Vries LM, van Baal PHM, Brouwer WBF. Future Costs in Cost-Effectiveness Analyses: Past, Present, Future. PharmacoEconomics 2019; 37 $119-130$

[30] Interpretation of Cost-Effectiveness Analyses. J Gen Intern Med 1998; 13: $716-717$

[31] Garber AM, Phelps CE. Economic foundations of cost-effectiveness analysis. J Health Econ 1997; 16: 1-31

[32] Fabritius MP, Holzgreve A, Knösel T et al. Incidental Finding of Endobronchial Metastasis by $18 \mathrm{~F}-\mathrm{FDG}$ PET/CT Leads to Change in Management in a Patient With Rectal Adenocarcinoma. Clin Nucl Med 2020; 45: 980-981

[33] Chambers JD, Lord J, Cohen JT et al. Illustrating Potential Efficiency Gains from Using Cost-Effectiveness Evidence to Reallocate Medicare Expenditures. Value Health 2013; 16: 629-638 